\title{
Syncope: new solutions for an old problem
}

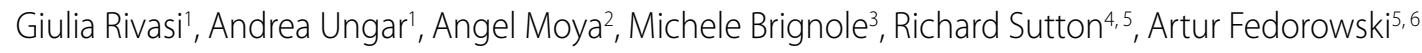 \\ 'Division of Geriatric and Intensive Care Medicine, University of Florence and Azienda Ospedaliero Universitaria Careggi, Florence, Italy \\ ${ }^{2}$ Cardiology and Arrhythmia Unit, University Hospital Dexeus, Barcelona, Spain \\ ${ }_{3}^{3}$ RCCS, Istituto Auxologico Italiano, Cardiology Unit and Department of Cardiovascular, Neural and Metabolic Sciences, S. Luca Hospital, Milan, Italy \\ ${ }^{4}$ Department of Cardiology, National Heart \& Lung Institute, Imperial College, Hammersmith Hospital Campus, London, UK \\ ${ }^{5}$ Department of Clinical Sciences, Lund University, Malmö, Sweden \\ ${ }^{6}$ Department of Cardiology, Karolinska University Hospital, and Department of Medicine, Karolinska Institute, Stockholm, Sweden
}

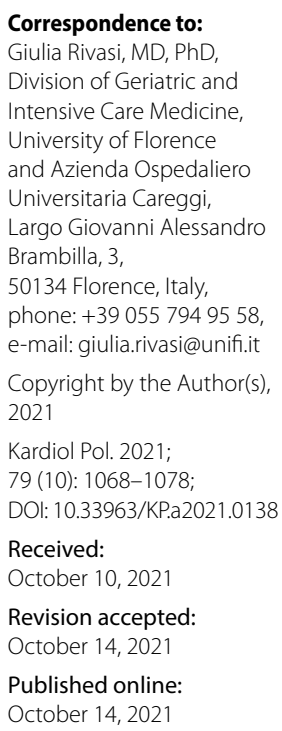

Correspondence to: Giulia Rivasi, MD, PhD, Division of Geriatric and Intensive Care Medicine, University of Florence and Azienda Ospedaliero Universitaria Careggi, Largo Giovanni Alessandro Brambilla, 3,

50134 Florence, Italy, phone: +39055 7949558 e-mail: giulia.rivasi@unifi.it Copyright by the Author(s), 2021

Kardiol Pol. 2021: 79 (10): 1068-1078; DOI: 10.33963/KP.a2021.0138 Received:

October 10, 2021

Revision accepted: October 14, 2021

Published online: October 14, 2021

\begin{abstract}
A B S TR A C T
Syncope is a frequent event in the general population. Approximately $1 \%-2 \%$ of all emergency department admissions are due to syncope and at least one-third of all people experience fainting in their life. Although consequences of cardiac syncope are generally feared, non-cardiac syncope is much more common and may be associated with severe injuries and quality-of-life impairment, particularly in older adults. Various diagnostic and therapeutic strategies have been created and implemented over decades, leading to significant improvements in diagnostic accuracy and treatment effectiveness. In recent years, diagnosis and treatment have further evolved according to an innovative approach focused on the hemodynamic mechanism underlying syncope, based upon the assumption that knowledge of the syncope mechanism is a prerequisite for effective syncope prevention and treatment. Therefore, a new classification of syncope has been proposed, which defines two main syncope phenotypes with different predominant mechanisms: the hypotensive phenotype, where hypotension or vasodepression prevails, and the bradycardic phenotype, where cardioinhibition prevails. Identification of syncope phenotype - bradycardic or hypotensive/vasodepressive - represents the first step towards personalized management of syncope, characterized by customized interventions for prevention. The present review aims to illustrate these new developments in the diagnosis and therapy of non-cardiac syncope within a mechanism-based perspective. Diagnosis and therapy of bradycardic and hypotensive phenotypes are discussed, with a focus on recent evidence.
\end{abstract}

Key words: reflex syncope, bradycardia, hypotension, cardioinhibition, vasodepression, low blood pressure

Kardiol Pol 2021; 79, 10: 1068-1078

This article is dedicated to our late friend and great syncope expert, Dr. Artur Pietrucha (1964-2020)

\section{INTRODUCTION}

Syncope is a very common event, affecting more than one third of the general population over the course of life. Although etiology is often benign, syncope is estimated to be severe in approximately $14 \%$ of cases, carrying a high risk of severe injuries and/or substantial impairment of the quality of life [1]. Even in the case of rare episodes, syncope may be responsible for serious fall-related complications, such as fractures and intracranial hemorrhage [2]. Moreover, recurrent syncope may cause patients' anxiety and restriction in social and working activities, thus affecting psychosocial functioning as in chronic diseases $[3,4]$.

The negative impact of syncope on patients' prognosis and quality of life is dramatically enhanced in older adults. At an advanced age, fall-related injuries frequently result in hospitalization, reduced mobility, and deconditioning, which may, in turn, lead to a decline of autonomy in daily life activities and increased risk of nursing-home admission [5]. Moreover, older adults frequently develop a "post-fall syndrome" characterized by fear of falling, depression, and sedentary lifestyles to avoid falling, which may further contribute to the functional decline [6]. Indeed, data from community-dwelling older adults sustaining severe fall-related injuries indicate that nearly half of individuals with no or mild-to-moderate pre-fall disability do not return to the pre-fall level of autonomy [7]. Apart from direct consequences, unexplained and often poorly managed syncope is associated with an increased risk of 
cardiovascular events and mortality [8]. Thus, accurate syncope diagnosis and effective prevention of recurrences represent an important healthcare challenge, particularly in older people.

Syncope is an old problem in medicine, discussed from the time of Hippocrates. However, in the $20^{\text {th }}$ century, the first specific diagnostic tools were designed, taking inspiration from electrocardiogram (ECG) recording methodology, experimental data, and aerospace medicine [9]. Diagnostic testing for syncope has then evolved over decades and structured pathways have been created, leading to significant improvements in the diagnostic capacity and accuracy $[10,11]$. In parallel, treatment strategies have been developed based on syncope etiology and clinical features [1]. Recently, some new concepts have been presented with particular reference to non-cardiac syncope.

In recent years, increasing attention has been focused on the hemodynamic mechanisms underlying syncope, and innovative diagnostic approaches have been proposed to achieve a mechanism-based diagnosis on the assumption that identification of the syncope mechanism is a necessary prerequisite for effective treatment. Concurrently, new treatment options have emerged, allowing for the implementation of mechanism-guided prevention of syncope recurrences.

The present review aims to illustrate new developments in the diagnosis and therapy of syncope, with special emphasis on non-cardiac syncope. Diagnosis and therapy of bradycardic and hypotensive phenotypes are discussed, with a focus on the most recent evidence.

\section{RECENT ADVANCES IN THE PATHOPHYSIOLOGY OF SYNCOPE}

WHAT'S NEW?

Deeper insights into the cardiovascular physiology of reflex syncope, including hemodynamic profile predisposition to syncope and relative contributions of vasodepression and cardioinhibition

A comparison of 6 community-based cohort studies with a large dataset of reflex syncope patients (64968 and 6516 observations, respectively) has revealed that individuals with reflex syncope have a different hemodynamic profile compared with the general population, characterized by lower systolic blood pressure (BP), higher diastolic $\mathrm{BP}$ and heart rate (HR) [12].

These hemodynamic features suggest that reflex syncope patients have reduced venous return and a lower stroke volume, which induces compensatory increases in $H R$ and vascular resistance. This hemodynamic framework draws fragile cardiovascular homeostasis, characterized by a latent predisposition to reflex syncope, which is counteracted by means of chronic activation of compensatory mechanisms to preserve organ perfusion. This implies that syncope may occur in the presence of triggering conditions, such as prolonged standing, that overcome the capacity of compensatory mechanisms, resulting in BP fall, cerebral hypoperfusion, and syncope. The reasons for these hemodynamic differences between syncope patients and the general population remain currently unknown, although assumptions have been made calling into question a lower circulating blood volume, a tendency to increased venous pooling [13], and abnormal neuroendocrine activation [14].

Recent research indicates that a neuroendocrine cascade is activated immediately before orthostatic syncope, characterized by epinephrine and vasopressin release [15-18]. Higher levels of epinephrine and vasopressin during Tilt Testing (TT) were found to be associated with a shorter time to syncope, suggesting an important contribution of the neuroendocrine system to individual syncope susceptibility $[15,16]$.

Individual hemodynamic features not only determine the predisposition to reflex syncope but also affect TT response. Another recent study has demonstrated that tilt-positive patients have lower systolic BP, diastolic BP, and HR compared with tilt-negative patients with similar presentations, independently of age and sex [19]. The above pathophysiological findings suggest the reduced capacity to compensate for lower systolic BP, expressed by lower diastolic BP and HR. Consistently, lower resting systolic BP ( $\leq 128 \mathrm{~mm} \mathrm{Hg}$ ) and absence of hypertension have been identified as independent predictors of TT positivity, confirming that reflex syncope susceptibility is strongly related to hemodynamic reserve, which is reduced in presence of lower BP [19]. Therefore, three different hemodynamic profiles can be outlined, including (1) individuals with stable cardiovascular homeostasis; (2) individuals with a predisposition to syncope and well-functioning compensatory mechanisms, allowing for increased tolerance to orthostatic stress and TT; (3) individuals with a more pronounced predisposition to syncope due to the suboptimal compensatory capacity, making them more prone to develop reflex syncope during TT.

In parallel with research investigating the hemodynamic profile determining predisposition to reflex syncope, some studies have allowed for a better understanding of hemodynamic changes occurring during TT-induced syncope. The BP fall occurring during reflex syncope is traditionally attributed to vasodepression, consisting of a reduction of sympathetic arteriolar tone and vascular peripheral resistance, and cardioinhibition, consisting of a vagal impact on sinus and atrioventricular nodes possibly leading to asystole [20]. A recent study by van Dijk et al. [21] suggests a different scenario, showing the reduced stroke volume as the first determinant of BP fall, with vascular resistance providing only a minor contribution. The reduced stroke volume is likely attributable to venous pooling, which is incompletely compensated by HR increase. Then, cardioinhibition follows starting as a weakening of initial compensatory HR increase, which adds to BP fall, thus 
Table 1. Mechanism-based classification of non-cardiac syncope

\begin{tabular}{c|c}
\hline Hypotensive phenotype & Non-cardiac syncope \\
\hline $\begin{array}{c}\text { Vasodepressor or mixed reflex syncope during TT } \\
\text { Vasodepressor or mixed carotid sinus syndrome }\end{array}$ & $\begin{array}{c}\text { Cardioinhibitory response to TT } \\
\text { Cardioinhibitory carotid sinus syndrome } \\
\text { Blood pressure falls detected on 24h-ambulatory blood pressure monitoring }\end{array}$ \\
Syncopal reflex asystole (>3 sec) or non-syncopal reflex asystole ( $>6$ sec) \\
detected by ILR \\
Low adenosine syncope
\end{tabular}

Abbreviations: ILR, implantable loop recorder; TT, Tilt Testing

acting as a turning point in the hemodynamic cascade of reflex syncope.

A detailed analysis of TT responses across age decades revealed that the relative contribution of cardioinhibition and vasodepression varies with age [22]. Prevalence of vasodepression progressively increases with advancing age while cardioinhibitory responses show an opposite trend, with a breakpoint around the age of 50, allowing the conclusion that the cardioinhibition component of reflex syncope declines with age. This gradient is likely to result from age-related changes in cardiovascular autonomic control, including decreased baroreceptor sensitivity, reduced cardiac responsiveness to beta-adrenergic stimulation, and a decline in vagal drive to the heart, which makes older adults more prone to develop vasodepressor reflex syncope [23, 24]. In addition, hypotensive medications and comorbidities may further contribute to vasodepression in older patients.

\section{CLASSIFYING NON-CARDIAC SYNCOPE}

\section{WHAT'S NEW?}

An innovative mechanism-based classification of non-cardiac syncope to guide therapy

Non-cardiac syncope has traditionally been classified based on its etiology and clinical presentation, i.e. as reflex syncope or autonomic failure (orthostatic hypotension), which is different from primary cardiac syncope, typically presenting as brady- or tachyarrhythmia [1]. Yet, recent advances in the understanding of the pathophysiology of syncope have set the stage for a new classification, which can also be helpful in the identification of the most suitable strategies for recurrence prevention. Non-cardiac syncope can be classified into different phenotypes according to the predominant underlying hemodynamic mechanism, i.e., hypotension (vasodepression) or bradycardia, corresponding to hypotensive and bradycardic phenotypes (Table 1) [2].

Syncope with hypotensive phenotype manifests as hypotension and is the prevalent mechanism typically occurring in patients with a constitutional or acquired (i.e., drug- or disease-induced) predisposition to hypotension, which can be referred to as hypotensive susceptibility [25]. While hypotension is present in all patients during syncope, hypotensive susceptibility implies a tendency to predominant vasodepression, often associated with reduced cardiac filling, which can be detected using TT, carotid sinus massage (CSM), or $24 \mathrm{~h}$-ambulatory blood pressure monitoring (ABPM) (Table 1). Patients with hypotensive susceptibility are most likely to benefit from treatment strategies that counteract hypotension.

In contrast, some patients show cardioinhibitory susceptibility, resulting in syncope with bradycardic phenotype, i.e., with a predominant cardioinhibitory mechanism. These patients are more likely to benefit from therapies that counteract bradycardia and asystole. Some degree of cardioinhibition is present in all patients during reflex syncope, but cardioinhibitory susceptibility is typical of those presenting with cardioinhibitory responses (including asystole) to TT and CSM with typical reflex features detected by long-term ECG monitoring [26]. Bradycardic phenotype also include syncope associated with idiopathic paroxysmal atrioventricular block and low plasma adenosine ("low adenosine syncope", see paragraph Bradycardic phenotype). Cardioinhibition is typically not present in patients with orthostatic hypotension, although neurogenic forms may be associated with cardiovascular autonomic dysfunction, chronotropic insufficiency, and reduced heart rate variability [27]. Further, the delayed form of orthostatic hypotension may lead to vasovagal reflex, which can be cardioinhibitory [28]. Hypotensive and bradycardic phenotypes may coexist in some patients, who require a comprehensive therapeutic approach to address both hypotensive and bradycardic susceptibility.

\section{MECHANISM-BASED APPROACH TO SYNCOPE DIAGNOSIS}

\section{WHAT'S NEW?}

The pivotal role of the syncope phenotype in diagnosis implying the growing importance of ambulatory blood pressure and ECG monitoring, and low-adenosine syncope as an emerging clinical entity.

Identifying the syncope phenotype represents the first step towards effective syncope prevention. The syncope phenotype reveals which hemodynamic mechanism should be addressed by customized therapeutic interventions. Thus, a mechanism-based approach is required, aimed at doc- 
umenting the correlation of syncope with hypotension and/or bradycardia.

\section{The hypotensive phenotype}

Hypotensive susceptibility leading to hypotensive phenotype syncope typically presents in patients with persistent or episodic hypotension, including orthostatic and postprandial hypotension [2].

Persistent hypotension may be constitutional or drug-related. Constitutional hypotension is a chronic condition characterized by inappropriately low BP in the absence of underlying diseases or specific causes. It is defined by World Health Organization as a systolic BP $<100 \mathrm{~mm} \mathrm{Hg}$ in women and $<110 \mathrm{~mm} \mathrm{Hg}$ in men [29] while some authors suggest considering the $5^{\text {th }}$ percentile of ambulatory BP as the lower limit of normal [30]. In these patients, low BP itself qualifies as a disease, with recurrent symptoms impairing the quality of life $[31,32]$. The prevalence reaches $4 \%$ in the general population, with higher rates in females [33].

Drug-related persistent hypotension is characterized by $\mathrm{BP}$ values persistently below the recommended target in patients receiving hypotensive medications [2]. It more frequently occurs in hypertensive patients, particularly in those receiving intensive antihypertensive treatment, which is more likely to result in hypotension-related complications [34, 35]. However, drug-related hypotension may also derive from non-cardiovascular medications with hypotensive effects [36].

Drug-related hypotension cannot be determined using a simple cut-off or definition. Drug-related hypotension occurs when unfavorable consequences of hypotension prevail over cardiovascular advantages of the BP reduction. Therefore, it can be stated that recommended BP targets correspond to the best balance of hypotensive and cardiovascular risk, i.e. BP values carrying the minimum cumulative risk of cardiovascular and hypotensive adverse events [37]. Such BP values are not uniform within the general population but rather vary greatly depending upon the age and frailty status. Indeed, old age and frailty are associated with an increased risk of hypotension, syncope, and falls, which severely impact functional autonomy and survival [38-40]. In parallel, the prognostic value of hypertension seems to reduce or even revert with age, thus increasing the risk/benefit ratio of BP reduction [41,42]. Drug-related hypotension should thus be defined accordingly, using personalized cut-off values based on individual hypotensive and cardiovascular risks [37].

Diagnosis of persistent hypotension - be it constitutional or drug-related - may be achieved using repeated office BPs or ABPM (Figure 1) [33, 43]. The latter may be especially useful in patients presenting office BP within the normal range, such as white-coat-effect potentially hampering detection of low BP $[43,44]$. Moreover, ABPM provides BP levels through 24 hours, permitting detection of episodic hypotension, profound BP drops in the context of normal mean BP.
ABPM is becoming recognized as a syncope diagnostic tool, with findings of both persistent and episodic hypotension (Table 2). ABPM may also reveal orthostatic, post-prandial, and post-exercise hypotension [1, 45-47], or hypotensive episodes following drug administration, as may be observed in Parkinsonian patients receiving dopaminergic drugs [46]. Moreover, ABPM may help to identify hypotensive susceptibility in reflex syncope. Recent data indicate that one or more episodes of daytime systolic BP $<90 \mathrm{~mm} \mathrm{Hg}$ on ABPM permit a diagnosis of hypotensive susceptibility in reflex syncope with $91 \%$ specificity and $32 \%$ sensitivity [48]. Therefore, ABPM has an important role in the diagnosis of syncope while being low cost and easy to perform. Taking into consideration its tolerability in older patients, even if cognitively impaired [49], ABPM is likely to increase in value in the diagnosis of syncope.

While diagnostic pathways of syncope expand with new resources, well-known instruments such as the active standing test and TT still maintain their clinical place [50]. The active standing test may identify episodic hypotension by showing orthostatic hypotension, which is extremely common in unexplained syncope [51]. Orthostatic hypotension may also be diagnosed during TT, which is particularly helpful for the identification of initial and delayed forms - the latter may herald classical orthostatic hypotension as a prodromal manifestation of autonomic dysfunction [51]. TT in reproducing syncope accurately documents underlying hemodynamics, which constitutes the treatment target. The diagnosis of the hypotensive phenotype is achieved during TT if syncope is reproduced with vasodepression or mixed responses, which suggest hypotension as the dominant syncope mechanism. TT has proven to have a high diagnostic yield of hypotensive phenotype while CSM may have a more limited role. In a study involving 3293 patients aged $>40$ years undergoing autonomic evaluation for suspected reflex syncope, the prevalence of hypotensive phenotype during TT and CSM was $53 \%$ and $1 \%$, respectively; $98 \%$ of patients with hypotensive phenotype were identified by TT, while $2 \%$ had both TT and positive CSM [52]. These data reaffirm the central role of TT in the mechanism-based diagnosis of non-cardiac syncope, particularly regarding the detection of hypotension susceptibility $[25,50]$. The diagnostic value of TT becomes even more prominent at old age when syncope diagnosis is more challenging due to frequent atypical manifestations, such as retrograde amnesia and unexplained falls. Patients' referrals for TT tend to increase with advancing age [22], parallel to an increase in atypical presentations which make achieving a diagnosis from clinical history alone more difficult.

\section{The bradycardic phenotype}

Non-cardiac syncope with bradycardic phenotype is diagnosed if asystole $>3$ seconds is documented during syncope, thus indicating cardioinhibitory reflex susceptibility [2]. Asystole is most commonly a sinus arrest or atrioventricular 
Severe, recurrent or unexplained non-cardiac syncope

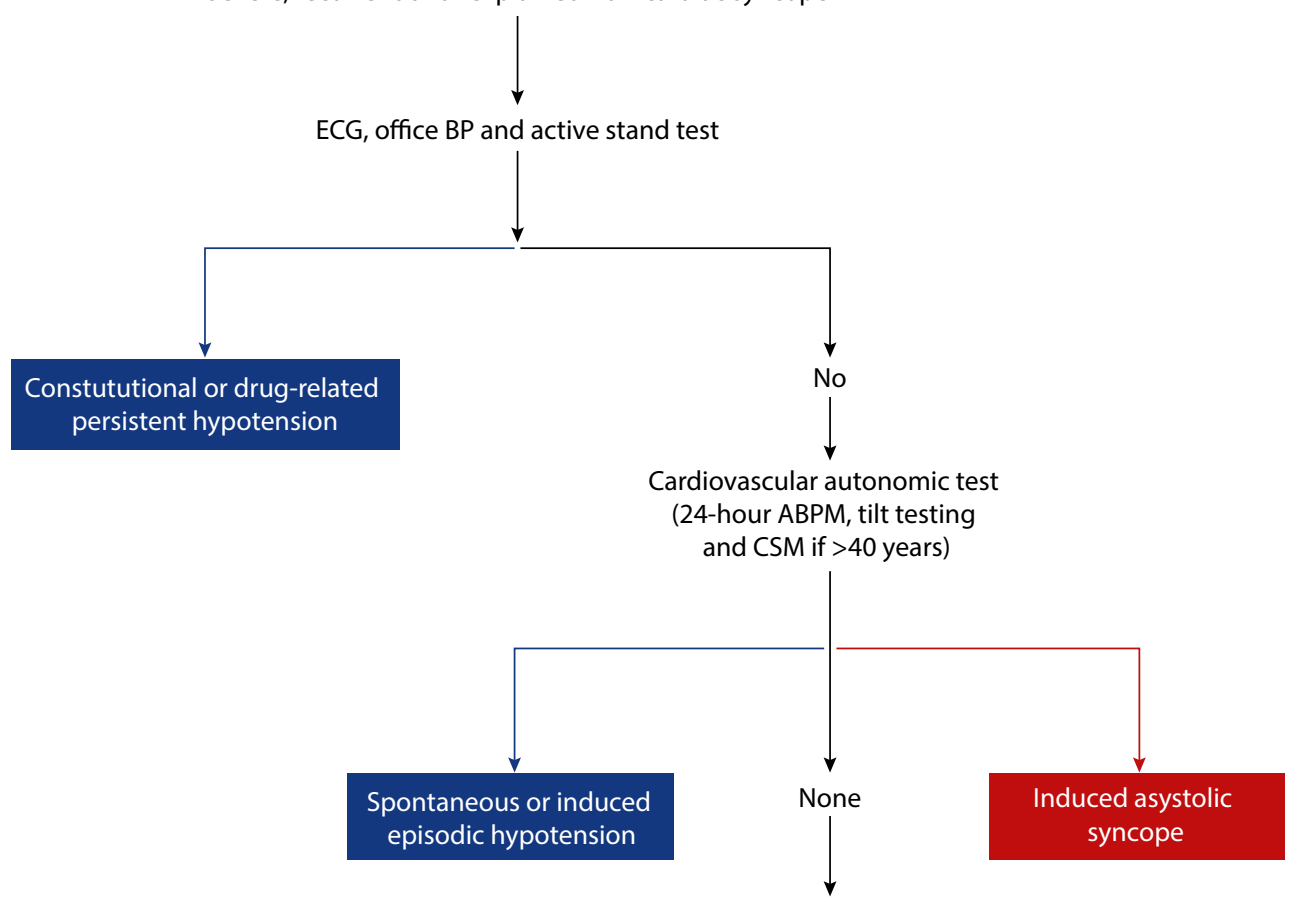

Prolonged ECG monitoring (ILR)
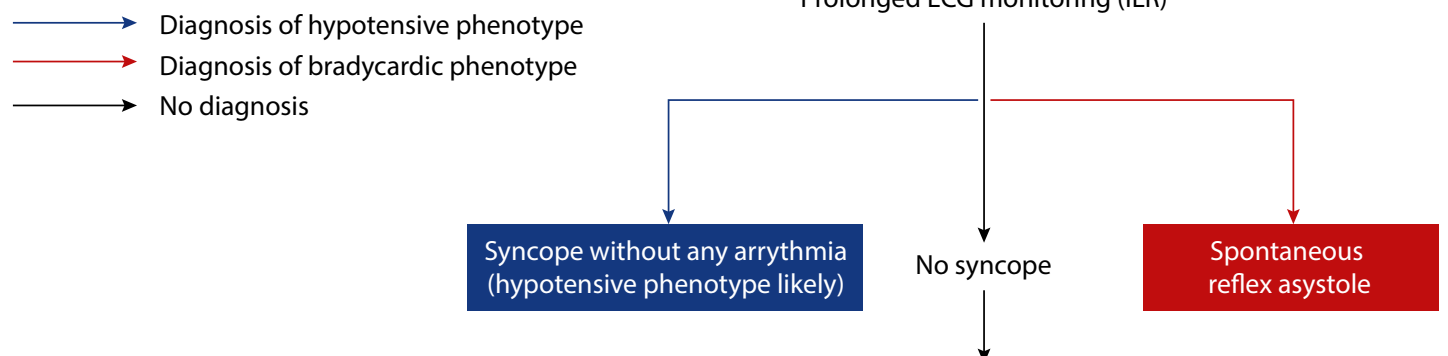

Re-appraisal

Figure 1. Diagnostic pathways for the hypotensive and bradycardic phenotype. Diagnosis of hypotensive phenotype may be achieved using office BPs, active stand test, 24-h ABPM or TT, showing constitutional/drug-related persistent or episodic hypotension (including orthostatic hypotension) (blue arrows). Diagnosis of bradycardic phenotype may be achieved using CSM, TT, or ILR, showing asystolic syncope (red arrows). A reappraisal should consider causes of loss of consciousness different from non-cardiac syncope, e.g, epilepsy, psychogenic pseudosyncope, falls, etc.

Abbreviations: ABPM, ambulatory blood pressure monitoring; BP, blood pressure; CSM, carotid sinus massage; ILR, implantable loop recorder

Table 2. Diagnostic role of 24-hour ambulatory blood pressure monitoring in patients with syncope.

\begin{tabular}{|c|c|c|}
\hline Diagnosis & Definition & BP cut-offs \\
\hline Constitutional hypotension & $\begin{array}{l}\text { Blood pressure values }<5^{\text {th }} \text { percentile } \\
\text { of blood pressure appropriate for sex } \\
\text { and time of day }[30,93]\end{array}$ & $\begin{array}{c}\text { Female } \\
\text { 24-hour SBP }<98 \mathrm{~mm} \mathrm{Hg} \\
\text { Daytime SBP }<105 \mathrm{~mm} \mathrm{Hg} \\
\text { Nighttime SBP }<92 \mathrm{~mm} \mathrm{Hg}\end{array}$ \\
\hline $\begin{array}{l}\text { Drug-related persistent hypo- } \\
\text { tension }\end{array}$ & $\begin{array}{l}\text { Blood pressure values persistently } \\
\text { below the recommended target [37] }\end{array}$ & $\begin{array}{l}\text { Customized blood pressure cut-off based on hypotensive and cardiovascular } \\
\text { risks [37] }\end{array}$ \\
\hline Hypotensive drops & Episodic hypotension & $\geq 1$ episodes of daytime SBP $<90 \mathrm{~mm} \mathrm{Hg}$ [48] \\
\hline Orthostatic hypotension & Blood pressure drops during standing & $\begin{array}{l}\text { Hypotensive episodes }<90 \mathrm{~mm} \text { Hg while standing (on patient's daily diary) may } \\
\text { suggest } \mathrm{OH} \\
\text { A reverse dipping profile frequently coexists in patients with autonomic failure } \\
\text { [46] }\end{array}$ \\
\hline Post-prandial hypotension & $\begin{array}{l}\text { Blood pressure falls during or imme- } \\
\text { diately after meals }\end{array}$ & $\begin{array}{l}\text { Drop in SBP of } 20 \mathrm{~mm} \mathrm{Hg} \text { within } 75 \text { min of eating meals, compared to the mean } \\
\text { of the last three blood pressure measurements before the meal }[45,47,94]\end{array}$ \\
\hline
\end{tabular}

Abbreviations: $\mathrm{OH}$, orthostatic hypotension; SBP, systolic blood pressure 
(AV) block which is not related to cardiac conduction disorders but is reflex $[53,54]$. Diagnosis may be achieved using CSM, TT, and prolonged ECG monitoring [1].

A cardioinhibitory positive response indicating a bradycardic phenotype is present in $10 \%$ of patients undergoing TT with a prevalence decreasing with age from $18 \%$ in individuals younger than 50 to $3 \%$ in older patients above the age of 80 [22]. Among patients undergoing CSM, the prevalence of bradycardic phenotype (i.e., cardioinhibitory carotid sinus syndrome) reaches $8 \%$ [52]. When performed in the same patients, CSM identifies approximately $60 \%$ of patients with bradycardic phenotype while $37 \%$ can be identified using TT, and $3 \%$ show a positive cardioinhibitory response in both tests [52]. Given this minimal overlap between TT and CSM, it can be stated that both tests are relevant to the diagnosis of bradycardic phenotype. Therefore, TT and CSM are complementary in the diagnosis of syncope, as both are needed for a thorough investigation of syncope mechanisms to target treatment interventions.

If both TT and CSM are negative, prolonged ECG monitoring using implantable loop recorder (ILR) may contribute to the mechanism-based diagnosis and identifying the bradycardic phenotype showing asystole during spontaneous syncope [55].

In the last decade, a new clinical entity has been defined in the context of non-cardiac syncope with bradycardic phenotype from prolonged ECG monitoring. Syncope with absent or very short prodrome has been observed in patients without cardiac disease (i.e., normal ECG and echocardiogram) and was frequently associated with sudden onset idiopathic AV block or - less frequently - sinus arrest $[56,57]$. Another common clinical feature is very low levels of plasma adenosine $(\leq 0.36 \mathrm{mmol} / \mathrm{l})[56,57]$, a purine derivative with cardiovascular effects. High-affinity A1 adenosine-receptors are located in the AV node and lesser quantity in the sinus node, where they mediate bradycardia [58]. When plasma adenosine is low, a high number of high-affinity $A 1$ receptors is available for binding due to upregulation, and a transient release of adenosine may be sufficient to block conduction in AV and sinus nodes, providing an explanation for a sudden AV block or sinus arrest. Thus, low plasma adenosine has been hypothesized to play a major role in the pathogenesis of syncope without prodromes with a normal heart and a normal electrocardiogram. Low adenosine syncope is considered an additional subtype of the bradycardic phenotype.

\section{EXISTING AND NEW STRATEGIES FOR SYNCOPE TREATMENT}

WHAT'S NEW?

Promising pharmacological treatment options for hypotensive syncope and a more definite role for cardiac pacing as a therapy for bradycardic non-cardiac syncope
Treatment interventions for non-cardiac syncope should now have a mechanism-guided approach, starting from hemodynamic and rhythm phenomena observed during diagnosis.

\section{Hypotensive phenotype}

\section{Medication review and optimization}

Alongside lifestyle measures aimed to counteract hypotensive susceptibility, a medication review and optimization should be carried out in all patients with syncope with the hypotensive phenotype (Figure 2) [1].

Medications with potential hypotensive effects should be revised and their indications reassessed to assess dose reduction or withdrawal. For antihypertensive medication careful assessment of BP control with deprescription if $\mathrm{BP}$ is below an individual-specific recommended target. Recent studies have provided data on the association between BP and hypotension-mediated adverse events, which may guide BP management in hypotensive susceptibility $[34,59,60]$. From this evidence, systolic BP targets of 130-140 mm Hg can be recommended in hypertensive patients with hypotensive susceptibility, as more intensive treatment is expected to substantially increase the hypotensive syncope risk [37]. Systolic BPs up to $160 \mathrm{~mm} \mathrm{Hg}$ can be tolerated in older adults with severe frailty or disability - a vulnerable population in which fall risk is extremely high and the benefits of BP reduction remain doubtful [42]. In patients with excessive BP control, deprescribing should be carried out starting with drug classes of higher hypotension risk, such as a-blockers, nitrates, diuretics, and non-selective $\beta$-blockers while prescribing should rely more on ACE-inhibitors and angiotensin receptor antagonists (Figure 2) [36]. Deprescribing of antihypertensive medications does not seem to increase mortality and cardiovascular risks and can be safely performed if BP control is deemed too intensive [61].

In patients with constitutional hypotension or untreated normal BPs, attention should be paid to potentially hypotensive psychoactive drugs. These include medications with a-mediated vasodilating effects, such as antipsychotics, trazodone, tricyclic antidepressants, and benzodiazepines, which have been reported to impair orthostatic BP response in older and deconditioned subjects [36]. Medication optimization should be aimed at achieving the lowest effective dose, and the use of prolonged-release formulations or fractioned doses should be considered to minimize hypotensive effects [62]. In patients with prostatic hyperplasia, a-blockers should only be prescribed in the presence of symptoms suggesting bladder outflow obstruction, and uroselective molecules, such as silodosin, should preferably be used, given their low impact on BP [36].

\section{Pharmacological therapies}

Despite non-pharmacological treatments, some patients may still complain of severe, recurrent syncope, leading to 


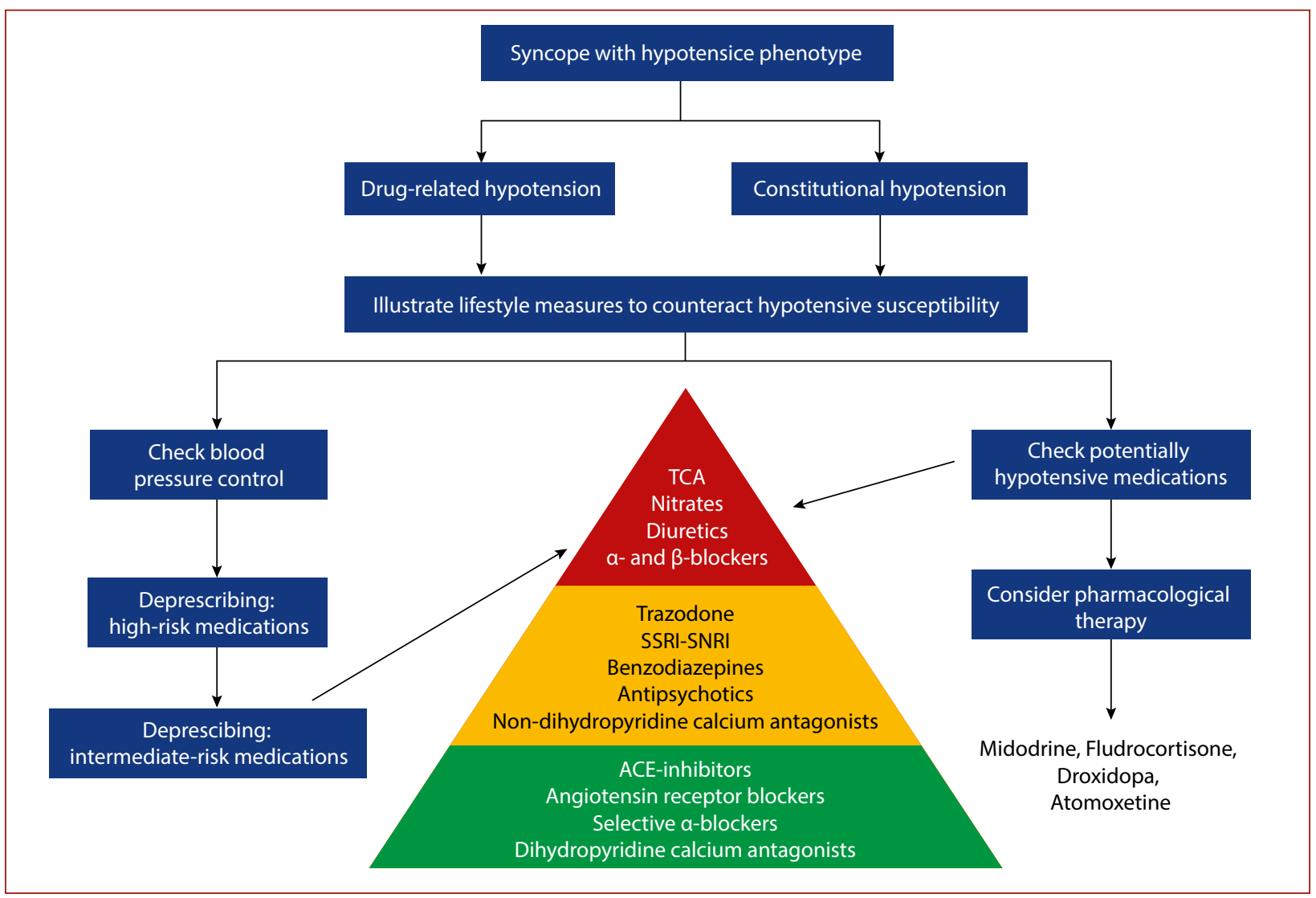

Figure 2. Therapeutic strategies for syncope with hypotensive phenotype. To guide deprescribing, the pyramid indicates the hypotensive risk associated with different drug classes: high risk (red), intermediate risk (yellow), low risk (green)

high injury risk and poor quality of life. They may benefit from pharmacological therapies to counterbalance hypotensive susceptibility.

The a1-agonist midodrine is one available option in patients with the hypotensive phenotype. Midodrine increases BP in patients with constitutional hypotension[63] and has demonstrated positive effects on symptoms due to neurogenic orthostatic hypotension and recurrent reflex syncope $[36,64,65]$. The recent Prevention of Syncope Trial (POST) 4 [66] re-emphasizes the value of midodrine in reflex syncope. The trial involved patients with severely symptomatic reflex syncope and showed a $40 \%$ relative risk reduction of recurrence using c. $10 \mathrm{mg} \mathrm{3/day} \mathrm{compared}$ with placebo; adverse events were modest and balanced in the two study groups. Notably, midodrine appeared more effective with baseline systolic BPs $>120 \mathrm{~mm} \mathrm{Hg}$. Midodrine is contraindicated in patients with hypertension, heart failure, urinary retention, and glaucoma.[36] Short half-life may limit long-term compliance.

As an alternative, the synthetic mineralocorticoid fludrocortisone may provide benefits in the hypotensive phenotype. In the POST 2 study [67], fludrocortisone ( $0.2 \mathrm{mg} /$ day) was found to reduce syncope recurrences by $49 \%$ in young patients with vasovagal syncope, with significantly greater benefits with lower baseline systolic $\mathrm{BP}(<110 \mathrm{~mm} \mathrm{Hg})$ and higher syncope frequency (>8 episodes/year) [67]. Moreover, fludrocortisone might improve orthostatic BP in patients with neurogenic orthostatic hypotension, although evidence in this clinical context is weak $[65,68,69]$. Side effects include hypokalemia, supine hypertension, and volume overload, prompting caution in patients with heart failure and renal dysfunction [36].

The norepinephrine prodrug droxidopa was found to improve standing BP and orthostatic tolerance in patients with neurogenic orthostatic hypotension, reducing symptoms in daily life [70-72]. Yet, evidence supporting droxidopa is moderate and long-term efficacy remains unclear [72].

Recent research has provided promising data on atomoxetine, a selective norepinephrine transporter (NET) inhibitor. Atomoxetine potentiates adrenergic drive to the heart, which may help to increase the heart rate, maintain cardiac output and BP during orthostatic stress. Atomoxetine was shown to reduce the risk of TT-induced syncope by attenuating reflex bradycardia and preventing the progression of presyncope to syncope $[73,74]$. Moreover, in a recent double-blind placebo-controlled trial, atomoxetine significantly reduced the risk of (pre)syncope and prolonged presyncope-free survival in vasovagal syncope with greater benefit in participants with systolic BP $<110 \mathrm{~mm} \mathrm{Hg}$ [75].

Pharmacological therapies are mainly targeted at patients who are not receiving hypotensive drugs if severe symptoms persist despite adherence to lifestyle measures. A pharmacological approach may be considered also in patients with drug-related hypotension in case hypoten- 


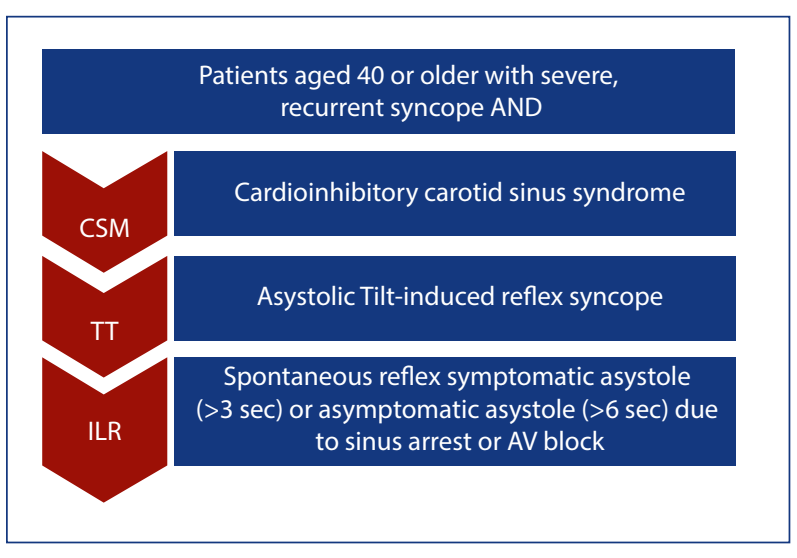

Figure 3. Indications for cardiac pacing in patients with bradycardic phenotype

Abbreviations: see Table 1 and Figure 1

sive medications are deemed necessary, e.g., in patients with Parkinson's disease receiving L-Dopa. In either case, pharmacological treatment should not aim at achieving pre-defined BP values, but rather improving symptoms and the quality of life. As available evidence on drug therapy is mainly in young adults [2], future studies should clarify the safety and effectiveness of pharmacological strategies in older patients.

\section{The bradycardic phenotype}

\section{Cardiac pacing}

Over the last decades, randomized controlled trials have provided evidence for the effectiveness of cardiac pacing in patients with predominant cardioinhibition documented by TT, CSM, or ILR, showing a significantly lower risk of syncope recurrence with pacing [2]. The SPAIN study [76] confirmed that pacing significantly reduces syncope events and time to the first recurrence in patients with cardioinhibitory TT-induced syncope (recurrence rate $9 \%$ and $46 \%$ in dual-chamber pacing with closed-loop stimulation vs. pacing-off, respectively). The results of the multicentre randomized placebo-controlled BIOSync trial have reinforced this conclusion, showing a significantly lower risk of (pre)syncope recurrence in patients with cardioinhibitory positive TT receiving dual-chamber pacing with closedloop stimulation compared with pacing-off (a $77 \%$ and $46 \%$ relative and absolute risk reduction at 2 years, respectively) [77]. Based on this evidence, the guidelines of the European Society of Cardiology (ESC) have upgraded the indication for pacing in reflex syncope from Ilb to I [78]. It must be understood that cardiac pacing is not always necessary but only indicated in patients aged $>40$-years affected by severe, recurrent, unpredictable syncope (i.e., often without prodrome) associated with a high risk of injuries [78]. At present, there is no evidence to support pacing in patients $<40$-years presenting even with severe symptoms [78]

Patients indicated for pacing can be identified by a multistep diagnostic pathway including CSM, TT, and ILR, as recommended by ESC guidelines [78]. Indications for cardiac pacing in syncope with the bradycardic phenotype are summarized in Figure 3.

Beneficial effects of pacing are related to the role of $\mathrm{HR}$ in the hemodynamic cascade of syncope. Pacing may prevent the reduction of $\mathrm{HR}$ at cardioinhibition onset if the sensor is ideal. An increase in HR will combat bradycardia and asystole and limit BP falls. Much depends on the fine-tuning of the sensor to individual needs. Patients with hypotensive susceptibility may be at risk of syncope recurrences after pacing, due to persistence of vasodepression. Syncope recurs after pacing in $\sim 15 \%-20 \%$ of patients, due to the coexistence of bradycardic and hypotensive phenotypes $[54,77,79,80]$. Specific treatment interventions against hypotensive susceptibility are necessary in addition to pacing to minimize recurrence risk.

TT has a pivotal role in patients' selection for cardiac pacing. Asystole on TT is highly specific for reflex syncope [81] and predictive of asystole in spontaneous syncope documented by ILR [82]. When TT-induced asystole occurs in a recurrently syncopal patient of $>40$-years, pacing is indicated. TT is also helpful to identify hypotensive susceptibility, which carries higher risks of syncope recurrences after pacing. In a meta-analysis involving 201 patients with asystolic syncope documented by ILR, benefits of cardiac pacing were greater in patients with negative TT ( $<6 \%$ recurrence risk within 3 years) while a positive TT independently predicted syncope recurrence after pacing (13\%-53\% recurrence risk; hazard ratio $4.3 ; 95 \%$ $\mathrm{Cl}, 1.4-13)$ [54]. Similar results have been reported in cardioinhibitory carotid sinus syndrome [83]. Video recording during TT further clarified recurrences in patients with the bradycardic phenotype; Saal et al. [84] demonstrated that $\sim 33 \%$ of patients with asystolic TT-induced syncope have late cardioinhibition, occurring $<3$ seconds before the loss of consciousness, which may limit or prevent pacemaker effectiveness against syncope recurrence.

\section{Theophylline}

Recent studies advocate theophylline as a promising treatment in patients with low adenosine syncope, raising a potential alternative to cardiac pacing. Theophylline is a non-selective adenosine receptor antagonist, which competes with adenosine for receptor binding. In patients with low adenosine syncope, theophylline may prevent A1 receptor activation with subsequent bradycardia when plasma adenosine increases. Moreover, theophylline antagonizes adenosine $A 2$ receptors mediating vasodilation, offering opposition to reflex vasodepression. Minor side effects including palpitations, headache, insomnia, and gastrointestinal complaints may limit tolerability.

Preliminary data from a small group of patients with low adenosine and asystolic syncope showed good responses to theophylline (400-600 mg twice daily) targeting a therapeutic plasma range of $12-18 \mu \mathrm{g} / \mathrm{ml}$ [57]. Furthermore, in a small study of low-adenosine syncope patients, a significant reduction of syncope and asystole burden during 
theophylline therapy compared with no treatment was observed [85]. The therapeutic role of theophylline has yet to be defined.

\section{Cardioneuroablation}

Cardioneuroablation (CNA) is an endocardial electrophysiological procedure to ablate epicardial postganglionic efferent parasympathetic fibers, which induces partial parasympathetic denervation of sinus and AV nodes [86-88]. CNA reduces vagal drive to the heart which mediates reflex cardioinhibition. It was introduced in 2005 by JC Pachon [88].

Preliminary data from case series and observational studies indicate successful vagal denervation and benefit on syncope burden [88-91]. However, available evidence on CNA is very limited and uncertainties persist on the methodology and long-term consequences of denervation $[2,92]$. There are no randomized controlled trials. Therefore, the use of CNA currently is experimental and requires more evidence.

\section{CONCLUSIONS}

Recently, diagnostic strategies and therapeutic options for non-cardiac syncope have evolved into a new approach, centered around an innovative, mechanism-based perspective. This new approach sets the basis for personalized management of syncope, characterized by customized interventions to prevent recurrences. Identification of syncope phenotype - bradycardic or hypotensive - represents the first step towards personalized syncope medicine. Future research should provide broader insights into customizing available treatment strategies.

\section{Article information}

\section{Conflict of interest: None declared.}

Open access: This article is available in open access under Creative Common Attribution-Non-Commercial-No Derivatives 4.0 International (CC BY-NC-ND 4.0) license, allowing to download articles and share them with others as long as they credit the authors and the publisher, but without permission to change them in any way or use them commercially. For commercial use, please contact the journal office at kardiologiapolska@ptkardio.pl.

How to cite: Rivasi G, Ungar A, Moya A, et al. Syncope: new solutions for an old problem. Kardiol Pol. 2021; 79(10): 1068-1078, doi: 10.33963/KP.a2021.0138.

\section{REFERENCES}

1. Brignole M, Moya A, de Lange FJ, et al. 2018 ESC Guidelines for the diagnosis and management of syncope. Eur Heart J. 2018; 39(21): 1883-1948, doi: 10.1093/eurheartj/ehy037, indexed in Pubmed: 29562304.

2. Brignole M, Rivasi G. New insights in diagnostics and therapies in syncope: a novel approach to non-cardiac syncope. Heart. 2021;107(11):864-873, doi: 10.1136/heartjnl-2020-318261, indexed in Pubmed: 33462120.

3. Linzer M, Pontinen M, Gold D, et al. Impairment of physical and psychosocial function in recurrent syncope. Journal of Clinical Epidemiology. 1991; 44(10): 1037-1043, doi: 10.1016/0895-4356(91)90005-t.

4. van Dijk N, Sprangers MA, Colman N, et al. Clinical factors associated with quality of life in patients with transient loss of consciousness. J Cardiovasc Electrophysiol. 2006; 17(9): 998-1003, doi: 10.1111/j.15408167.2006.00533.x, indexed in Pubmed: 16764705.
5. Gill TM, Murphy TE, Gahbauer EA, et al. Association of injurious falls with disability outcomes and nursing home admissions in community-living older persons. Am J Epidemiol. 2013; 178(3): 418-425, doi: 10.1093/aje/kws554, indexed in Pubmed: 23548756.

6. Vellas BJ, Wayne SJ, Romero LJ, et al. Fear of falling and restriction of mobility in elderly fallers. Age Ageing. 1997; 26(3): 189-193, doi: 10.1093/ageing/26.3.189, indexed in Pubmed: 9223714.

7. Gill TM, Murphy TE, Gahbauer EA, et al. The course of disability before and after a serious fall injury. JAMA Intern Med. 2013; 173(19): 1780-1786, doi: 10.1001/jamainternmed.2013.9063, indexed in Pubmed: 23958741.

8. Yasa $E$, Ricci $F$, Magnusson $M$, et al. Cardiovascular risk after hospitalisation for unexplained syncope and orthostatic hypotension. Heart. 2018; 104(6): 487-493, doi: 10.1136/heartjnl-2017-311857, indexed in Pubmed: 28775101.

9. Rivasi $G$, Rafanelli $M$, Ungar A. Usefulness of tilt testing and carotid sinus massage for evaluating reflex syncope. Am J Cardiol. 2018; 122(3): 517520, doi: 10.1016/j.amjcard.2018.04.033, indexed in Pubmed: 29954601.

10. Ungar A, Tesi F, Chisciotti VM, et al. Assessment of a structured management pathway for patients referred to the Emergency Department for syncope: results in a tertiary hospital. Europace. 2016; 18(3):457-462, doi: 10.1093/europace/euv106, indexed in Pubmed: 25976905.

11. Brignole $M$, Ungar A, Casagranda I, et al. Prospective multicentre systematic guideline-based management of patients referred to the Syncope Units of general hospitals. Europace. 2010; 12(1): 109-118, doi: 10.1093/europace/eup370, indexed in Pubmed: 19948566.

12. Brignole M, Rivasi G, Sutton R, et al. Low-blood pressure phenotype underpins the tendency to reflex syncope. J Hypertens. 2021;39(7): 1319-1325, doi: 10.1097/HJH.0000000000002800, indexed in Pubmed: 33560050.

13. Stewart JM, Medow MS, Sutton R, et al. Mechanisms of vasovagal syncope in the young: reduced systemic vascular resistance versus reduced cardiac output. J Am Heart Assoc. 2017; 6(1), doi: 10.1161/JAHA.116.004417, indexed in Pubmed: 28100453.

14. Nilsson D, Sutton R, Tas W, et al. Orthostatic changes in hemodynamics and cardiovascular biomarkers in dysautonomic patients. PLoS One. 2015; 10(6): e0128962, doi: 10.1371/journal.pone.0128962, indexed in Pubmed: 26053073.

15. Kohno R, Detloff BLS, Chen LY, et al. Greater early epinephrine rise with head-up posture: A marker of increased syncope susceptibility in vasovagal fainters. J Cardiovasc Electrophysiol. 2019; 30(3): 289-296, doi: 10.1111/jce.13792, indexed in Pubmed: 30431678.

16. Torabi P, Ricci F, Hamrefors V, et al. Impact of cardiovascular neurohormones on onset of vasovagal syncope induced by head-up tilt. J Am Heart Assoc. 2019; 8(12): e012559, doi: 10.1161/JAHA.119.012559, indexed in Pubmed: 31208249.

17. Lindenberger $\mathrm{M}$, Fedorowski $\mathrm{A}$, Melander $\mathrm{O}$, et al. Cardiovascular biomarkers and echocardiographic findings at rest and during graded hypovolemic stress in women with recurrent vasovagal syncope. J Cardiovasc Electrophysiol. 2019; 30(12): 2936-2943, doi: 10.1111/jce.14207, indexed in Pubmed: 31578800.

18. Fedorowski A, Burri P, Struck J, et al. Novel cardiovascular biomarkers in unexplained syncopal attacks: the SYSTEMA cohort. J Intern Med. 2013; 273(4): 359-367, doi: 10.1111/joim.12043, indexed in Pubmed: 23510366.

19. Fedorowski $A$, Rivasi $G$, Torabi $P$, et al. Underlying hemodynamic differences are associated with responses to tilt testing. Sci Rep. 2021; 11(1): 17894, doi: 10.1038/s41598-021-97503-0, indexed in Pubmed: 34504263.

20. Wieling W, Jardine DL, de Lange FJ, et al. Cardiac output and vasodilation in the vasovagal response: An analysis of the classic papers. Heart Rhythm. 2016;13(3): 798-805, doi: 10.1016/j.hrthm.2015.11.023, indexed in Pubmed: 26598322.

21. van Dijk JG, Ghariq M, Kerkhof Fl, et al. Novel methods for quantification of vasodepression and cardioinhibition during tilt-induced vasovagal syncope. Circ Res. 2020; 127(5): e126-e138, doi: 10.1161/CIRCRESAHA.120.316662, indexed in Pubmed: 32460687.

22. Rivasi $G$, Torabi $P$, Secco $G$, et al. Age-related tilt test responses in patients with suspected reflex syncope. Europace. 2021; 23(7): 1100-1105, doi: 10.1093/europace/euab024, indexed in Pubmed: 33564843.

23. Monahan KD. Effect of aging on baroreflex function in humans. Am J Physiol Regul Integr Comp Physiol. 2007; 293(1): R3-RR12, doi: 10.1152/ajpregu.00031.2007, indexed in Pubmed: 17442786. 
24. Pfeifer M, Weinberg C, Cook D, et al. Differential changes of autonomic nervous system function with age in man. The American Journal of Medicine. 1983; 75(2): 249-258, doi: 10.1016/0002-9343(83)91201-9.

25. Sutton R, Brignole M. Twenty-eight years of research permit reinterpretation of tilt-testing: hypotensive susceptibility rather than diagnosis. Eur Heart J.2014; 35(33): 2211-2212, doi: 10.1093/eurheartj/ehu255, indexed in Pubmed: 24980488.

26. Brignole M, Moya A, Menozzi C, et al. Proposed electrocardiographic classification of spontaneous syncope documented by an implantable loop recorder. Europace. 2005; 7(1): 14-18, doi: 10.1016/j.eupc.2004.11.001, indexed in Pubmed: 15670961.

27. Freeman $R$, Abuzinadah AR, Gibbons $C$, et al. Orthostatic hypotension: JACC state-of-the-art review. J Am Coll Cardiol. 2018; 72(11): 1294-1309, doi: 10.1016/j.jacc.2018.05.079, indexed in Pubmed: 30190008

28. Fedorowski A, van Wijnen VK, Wieling W. Delayed orthostatic hypotension and vasovagal syncope: a diagnostic dilemma. Clin Auton Res. 2017;27(4): 289-291, doi: 10.1007/s10286-017-0424-8, indexed in Pubmed: 28550504.

29. WHO Expert Committee on Arterial Hypertension \& World Health Organization. Arterial hypertension: report of a WHO expert committee [ $\bigotimes$ meeting held in Geneva from 13 to 21 March 1978]; 1978区: 7-56.

30. Owens PE, Lyons SP, O'Brien ET. Arterial hypotension: prevalence of low blood pressure in the general population using ambulatory blood pressure monitoring. J Hum Hypertens. 2000; 14(4): 243-247, doi: 10.1038/sj. jhh.1000973, indexed in Pubmed: 10805049.

31. Pemberton J. Does constitutional hypotension exist? BMJ. 1989; 298(6674):660-662, doi: 10.1136/bmj.298.6674.660, indexed in Pubmed 2496798.

32. Jacob G, Barbic F, Glago M, et al. Cardiovascular autonomic profile in women with constitutional hypotension. JHypertens. 2018;36(10):2068-2076, doi: 10.1097/HJH.0000000000001790, indexed in Pubmed: 29781840.

33. De Buyzere $M$, Clement DL, Duprez D. Chronic low blood pressure: a review .Cardiovasc Drugs Ther. 1998; 12(1):29-35, doi: 10.1023/a:1007729229483, indexed in Pubmed: 9607130.

34. Sim JJ, Zhou H, Bhandari S, et al. Low systolic blood pressure from treatment and association with serious falls/syncope. Am J Prev Med. 2018; 55(4): 488-496, doi: 10.1016/j.amepre.2018.05.026, indexed in Pubmed: 30166081.

35. Sink KM, Evans GW, Shorr Rl, et al. Syncope, hypotension, and falls in the treatment of hypertension: results from the randomized clinical systolic blood pressure intervention trial. J Am Geriatr Soc. 2018; 66(4): 679-686, doi: 10.1111/jgs.15236, indexed in Pubmed: 29601076.

36. Rivasi G, Rafanelli M, Mossello E, et al. Drug-Related orthostatic hypotension: beyond anti-hypertensive medications. Drugs Aging. 2020; 37(10): 725-738, doi: 10.1007/s40266-020-00796-5, indexed in Pubmed: 32894454.

37. Rivasi $G$, Brignole $M$, Rafanelli $M$, et al. Blood pressure management in hypertensive patients with syncope: how to balance hypotensive and cardiovascular risk. J Hypertens. 2020; 38(12): 2356-2362, doi: 10.1097/HJH.0000000000002555, indexed in Pubmed: 32649639.

38. Scuteri A, Modestino A, Frattari A, et al. Occurrence of hypotension in older participants. Which 24-hour ABPM parameter better correlate with? J Gerontol A Biol Sci Med Sci. 2012; 67(7):804-810, doi: 10.1093/gerona/glr232, indexed in Pubmed: 22227524.

39. Ceccofiglio A, Mussi C, Rafanelli M, et al. Increasing prevalence of orthostatic hypotension as a cause of syncope with advancing age and multimorbidity. J Am Med Dir Assoc. 2019; 20(5):586-588, doi: 10.1016/j. jamda.2019.01.149, indexed in Pubmed: 30926410.

40. Ungar A, Mussi C, Ceccofiglio A, et al. Etiology of syncope and unexplained falls in elderly adults with dementia: Syncope and Dementia (SYD) study J Am Geriatr Soc. 2016;64(8): 1567-1573, doi: 10.1111/jgs.14225, indexed in Pubmed: 27351866.

41. Liang $Y$, Fratiglioni $L$, Wang $R$, et al. Effects of biological age on the associations of blood pressure with cardiovascular and non-cardiovascular mortality in old age: A population-based study. Int J Cardiol. 2016; 220 508-513, doi: 10.1016/j.ijcard.2016.06.118, indexed in Pubmed: 27390978 .

42. Rivasi G, Tortù V, D'Andria MF, et al. Hypertension management in frail older adults: a gap in evidence. J Hypertens. 2021; 39(3): 400-407, doi: 10.1097/HJH.0000000000002685, indexed in Pubmed: 33239551.

43. Stergiou GS, Palatini P, Parati G, et al. 2021 European Society of Hypertension practice guidelines for office and out-of-office blood pressure measurement. J Hypertens. 2021; 39(7): 1293-1302, doi: 10.1097/HJH.0000000000002843, indexed in Pubmed: 33710173.

44. Ishikawa J, Ishikawa Y, Edmondson D, et al. Age and the difference between awake ambulatory blood pressure and office blood pressure: a meta-analysis. Blood Press Monit. 2011; 16(4): 159-167, doi: 10.1097/MBP.0b013e328346d603, indexed in Pubmed: 21558845.

45. Vallelonga $F$, Romagnolo $A$, Merola $A$, et al. Detection of orthostatic hypotension with ambulatory blood pressure monitoring in parkinson's disease. Hypertens Res. 2019; 42(10): 1552-1560, doi: 10.1038/s41440019-0267-x, indexed in Pubmed: 31118487.

46. Stuebner E, Vichayanrat E, Low DA, et al. Twenty-four hour non-invasive ambulatory blood pressure and heart rate monitoring in Parkinson's disease. Front Neurol.2013; 4:49, doi: 10.3389/fneur.2013.00049, indexed in Pubmed: 23720648.

47. Alquadan KF, Singhania G, Koratala A, et al. Office orthostatic blood pressure measurements and ambulatory blood pressure monitoring in the prediction of autonomic dysfunction. Clin Hypertens. 2017; 23:3, doi: 10.1186/s40885-016-0059-4, indexed in Pubmed: 28331633.

48. Giulia Rivasi, Antonella Groppelli, Michele Brignole, Davide Soranna, Antonella Zambon, Grzegorz Bilo, Martino Pengo, Bashaaer Sharad, Viktor Hamrefors, Martina Rafanelli, Giuseppe Dario Testa, Richard Sutton, Andrea Ungar, Artur Fedorowski GP Ambulatory blood pressure monitoring: a new diagnostic approach for detection of hypotension in reflex syncope. 2021(SynABPM 1 study): Submitted.

49. Conroy SP, Harrison JK, Van Der Wardt V, et al. Ambulatory blood pressure monitoring in older people with dementia: a systematic review of tolerability. Age Ageing. 2016; 45(4): 456-462, doi: 10.1093/ageing/afw050, indexed in Pubmed: 27055877

50. Sutton R, Fedorowski $A$, Olshansky $B$, et al. Tilt testing remains a valuable asset. Eur Heart J. 2021; 42(17): 1654-1660, doi: 10.1093/eurheartj/ehab084, indexed in Pubmed: 33624801.

51. Torabi P, Ricci F, Hamrefors V, et al. Classical and delayed orthostatic hypotension in patients with unexplained syncope and severe orthostatic intolerance. Front Cardiovasc Med. 2020; 7:21, doi: 10.3389/fcvm.2020.00021, indexed in Pubmed: 32154270

52. Brignole $M$, Kessisoglu F, Croci $F$, et al. Complementary effectiveness of carotid sinus massage and tilt testing for the diagnosis of reflex syncope in patients older than 40 years: a cohort study. Europace. 2020;22(11):17371741, doi: 10.1093/europace/euaa204, indexed in Pubmed: 33078193.

53. Sutton R. Reflex Atrioventricular Block. Front Cardiovasc Med. 2020; 7:48, doi: 10.3389/fcrm.2020.00048, indexed in Pubmed: 32309297.

54. Brignole M, Deharo JC, Menozzi C, et al. The benefit of pacemaker therapy in patients with neurally mediated syncope and documented asystole: a meta-analysis of implantable loop recorder studies. Europace. 2018; 20(8): 1362-1366, doi: 10.1093/europace/eux321, indexed in Pubmed: 29267867.

55. Moya A, Brignole $M$, Menozzi $C$, et al. Mechanism of syncope in patients with isolated syncope and in patients with tilt-positive syncope. Circulation. 2001; 104(11): 1261-1267, doi: 10.1161/hc3601.095708, indexed in Pubmed: 11551877.

56. Deharo JC, Guieu R, Mechulan A, et al. Syncope without prodromes in patients with normal heart and normal electrocardiogram: a distinct entity. J Am Coll Cardiol. 2013;62(12): 1075-1080, doi: 10.1016/j.jacc.2013.05.060, indexed in Pubmed: 23810895.

57. Brignole M, Guieu R, Tomaino M, et al. Mechanism of syncope without prodromes with normal heart and normal electrocardiogram. Heart Rhythm. 2017; 14(2):234-239, doi: 10.1016/j.hrthm.2016.08.046, indexed in Pubmed: 27639455.

58. Joulia $F$, Coulange $M$, Lemaitre $F$, et al. Plasma adenosine release is associated with bradycardia and transient loss of consciousness during experimental breath-hold diving. Int J Cardiol. 2013; 168(5): e138-e141, doi: 10.1016/j.ijcard.2013.08.053, indexed in Pubmed: 24016542.

59. Solari $D$, Tesi $F$, Unterhuber $M$, et al. Stop vasodepressor drugs in reflex syncope: a randomised controlled trial. Heart. 2017; 103(6):449-455, doi: 10.1136/heartjnl-2016-309865, indexed in Pubmed: 27664002.

60. Bress AP, Kramer H, Khatib R, et al. Potential Deaths Averted and Serious Adverse Events Incurred From Adoption of the SPRINT (Systolic Blood Pressure Intervention Trial) Intensive Blood Pressure Regimen in the United States: Projections From NHANES (National Health and Nutrition Examination Survey). Circulation. 2017; 135(17): 1617-1628, doi: 10.1161/CIRCULATIONAHA.116.025322, indexed in Pubmed: 28193605. 
61. van der Wardt V, Harrison JK, Welsh T, et al. Withdrawal of antihypertensive medication: a systematic review. J Hypertens. 2017; 35(9): 1742-1749, doi: 10.1097/HJH.0000000000001405, indexed in Pubmed: 28486271.

62. Verhaeverbeke I, Mets T. Drug-induced orthostatic hypotension in the elderly: avoiding its onset. Drug Saf. 1997; 17(2): 105-118, doi: 10.2165/00002018-199717020-00003, indexed in Pubmed: 9285201.

63. Duschek $\mathrm{S}$, Heiss $\mathrm{H}$, Buechner $\mathrm{B}$, et al. Hemodynamic determinants of chronic hypotension and their modification through vasopressor application. J Physiol Sci. 2009; 59(2): 105-112, doi: 10.1007/s12576-008-0015-5, indexed in Pubmed: 19340550.

64. Izcovich A, González Malla C, Manzotti M, et al. Midodrine for orthostatic hypotension and recurrent reflex syncope: A systematic review. Neurology. 2014; 83(13): 1170-1177, doi: 10.1212/WNL.0000000000000815, indexed in Pubmed: 25150287.

65. Eschlböck S, Wenning G, Fanciulli A. Evidence-based treatment of neurogenic orthostatic hypotension and related symptoms. J Neural Transm (Vienna). 2017; 124(12): 1567-1605, doi: 10.1007/s00702-017-1791-y, indexed in Pubmed: 29058089.

66. Sheldon R, Faris P, Tang A, et al. Midodrine for the prevention of vasovagal syncope: a randomized clinical trial. Ann Intern Med. 2021 [Epub ahead of print], doi: 10.7326/M20-5415, indexed in Pubmed: 34339231.

67. Sheldon R, Raj SR, Rose MS, et al. POST 2 Investigators. Fludrocortisone for the prevention of Vasovagal syncope: a randomized, placebo-controlled trial. J Am Coll Cardiol. 2016; 68(1): 1-9, doi: 10.1016/j.jacc.2016.04.030, indexed in Pubmed: 27364043.

68. Hakamäki T, Rajala T, Lehtonen A. Ambulatory 24-hour blood pressure recordings in patients with Parkinson's disease with or without fludrocortisone. Int J Clin Pharmacol Ther. 1998; 36(7): 367-369, indexed in Pubmed: 9707350.

69. van Lieshout JJ, ten Harkel AD, Wieling W. Fludrocortisone and sleeping in the head-up position limit the postural decrease in cardiac output in autonomic failure. Clin Auton Res. 2000; 10(1): 35-42, doi: 10.1007/BF02291388, indexed in Pubmed: 10750642.

70. Kaufmann H, Freeman R, Biaggioni I, et al. Droxidopa for neurogenic orthostatic hypotension: a randomized, placebo-controlled, phase 3 trial. Neurology. 2014; 83(4): 328-335, doi: 10.1212/WNL.0000000000000615, indexed in Pubmed: 24944260.

71. Hauser RA, Isaacson S, Lisk JP, et al. Droxidopa for the short-term treatment of symptomatic neurogenic orthostatic hypotension in Parkinson's disease (nOH306B). Mov Disord. 2015; 30(5): 646-654, doi: 10.1002/mds.26086, indexed in Pubmed: 25487613.

72. Keating GM. Droxidopa: a review of its use in symptomatic neurogenic orthostatic hypotension. Drugs. 2015; 75(2): 197-206, doi: 10.1007/s40265014-0342-1, indexed in Pubmed: 25559422.

73. Sheldon RS, Lei L, Guzman JC, et al. A proof of principle study of atomoxetine for the prevention of vasovagal syncope: the Prevention of Syncope Trial VI. Europace. 2019; 21(11): 1733-1741, doi: 10.1093/europace/euz250, indexed in Pubmed: 31538180.

74. Sheldon RS, Ritchie D, McRae M, et al. Norepinephrine transport inhibition for treatment of vasovagal syncope. J Cardiovasc Electrophysiol. 2013; 24(7): 799-803, doi: 10.1111/jce.12111, indexed in Pubmed: 23444896.

75. Tajdini $\mathrm{M}$, Aminorroaya $\mathrm{A}$, Tavolinejad $\mathrm{H}$, et al. Atomoxetine as an adjunct to nonpharmacological treatments for preventing vasovagal attacks in patients with recurrent vasovagal syncope: A pilot randomized-controlled trial. Int J Cardiol Heart Vasc. 2021; 34: 100789, doi: 10.1016/j. ijcha.2021.100789, indexed in Pubmed: 34027030.

76. Baron-Esquivias G, Morillo CA, Moya-Mitjans A, et al. Dual-Chamber pacing with closed loop stimulation in recurrent reflex vasovagal syncope: the SPAIN study. J Am Coll Cardiol. 2017; 70(14): 1720-1728, doi: 10.1016/j. jacc.2017.08.026, indexed in Pubmed: 28958328.

77. Brignole M, Russo V, Arabia F, et al. Cardiac pacing in severe recurrent reflex syncope and tilt-induced asystole. Eur Heart J. 2021; 42(5): 508-516, doi: 10.1093/eurheartj/ehaa936, indexed in Pubmed: 33279955.

78. Glikson M, Nielsen JC, Kronborg MB, et al. 2021 ESC Guidelines on cardiac pacing and cardiac resynchronization therapy. Eur Heart J. 2021; 42(35): 3427-3520, doi: 10.1093/eurheartj/ehab364, indexed in Pubmed: 34455430 .
79. Rivasi G, Solari D, Rafanelli M, et al. Incidence and predictors of syncope recurrence after cardiac pacing in patients with carotid sinus syndrome. Int J Cardiol. 2018; 266: 119-123, doi: 10.1016/j.jjcard.2018.03.144, indexed in Pubmed: 29887427.

80. Yasa E, Ricci F, Holm H, et al. Pacing therapy in the management of unexplained syncope: a tertiary care centre prospective study. Open Heart. 2019; 6(1): e001015, doi: 10.1136/openhrt-2019-001015, indexed in Pubmed: 30997138.

81. Brignole $M$, Tomaino $M$, Gargaro A. Vasovagal syncope with asystole: the role of cardiac pacing. Clin Auton Res. 2017; 27(4): 245-251, doi: 10.1007/s10286-017-0441-7, indexed in Pubmed: 28669088.

82. Brignole $M$, Donateo $P$, Tomaino $M$, et al. Benefit of pacemaker therapy in patients with presumed neurally mediated syncope and documented asystole is greater when tilt test is negative. Circ Arrhythmia Electrophysiol. 2014; 7(1): 10-16, doi: 10.1161/circep.113.001103.

83. Solari D, Maggi R, Oddone $D$, et al. Clinical context and outcome of carotid sinus syndrome diagnosed by means of the ,method of symptoms'. Europace. 2014; 16(6): 928-934, doi: 10.1093/europace/eut283, indexed in Pubmed: 24058183.

84. Saal DP, Thijs RD, van Zwet EW, et al. Temporal relationship of asystole to onset of transient loss of consciousness in tilt-induced reflex syncope. JACC Clin Electrophysiol. 2017; 3(13): 1592-1598, doi: 10.1016/j. jacep.2017.07.006, indexed in Pubmed: 29759842.

85. Brignole $M$, lori $M$, Solari $D$, et al. Efficacy of theophylline in patients with syncope without prodromes with normal heart and normal ECG. Int J Cardiol. 2019; 289: 70-73, doi: 10.1016/j.ijcard.2019.03.043, indexed in Pubmed: 30928258.

86. Hu F, Zheng L, Liang E, et al. Right anterior ganglionated plexus: The primary target of cardioneuroablation? Heart Rhythm. 2019; 16(10): 1545-1551, doi: 10.1016/j.hrthm.2019.07.018, indexed in Pubmed: 31330187.

87. Sun $\mathrm{W}$, Zheng $\mathrm{L}$, Qiao $\mathrm{Yu}$, et al. Catheter ablation as a treatment for vasovagal syncope: long-term outcome of endocardial autonomic modification of the left atrium. J Am Heart Assoc. 2016; 5(7), doi: 10.1161/JAHA.116.003471, indexed in Pubmed: 27402231.

88. Pachon JC, Pachon El, Cunha Pachon MZ, et al. Catheter ablation of severe neurally meditated reflex (neurocardiogenic or vasovagal) syncope: cardioneuroablation long-term results. Europace. 2011;13(9): 1231-1242, doi: 10.1093/europace/eur163, indexed in Pubmed: 21712276.

89. Debruyne $P$, Rossenbacker $T$, Janssens $L$, et al. Durable physiological changes and decreased syncope burden 12 months after unifocal right-sided ablation under computed tomographic guidance in patients with neurally mediated syncope or functional sinus node dysfunction. Circ Arrhythm Electrophysiol. 2021; 14(6): e009747, doi: 10.1161/CIRCEP.120.009747, indexed in Pubmed: 33999698.

90. Calo L, Rebecchi M, Sette A, et al. Catheter ablation of right atrial ganglionated plexi to treat cardioinhibitory neurocardiogenic syncope: a long-term follow-up prospective study. J Interv Card Electrophysiol. 2021; 61(3): 499-510, doi: 10.1007/s10840-020-00840-9, indexed in Pubmed: 32766945

91. Aksu T, Güler TE, Bozyel S, et al. Cardioneuroablation in the treatment of neurally mediated reflex syncope: a review of the current literature. Turk Kardiyol Dern Ars. 2017; 45(1): 33-41, doi: 10.5543/tkda.2016.55250, indexed in Pubmed: 28106018.

92. Wieling W, Jardine DL. Cardioneuroablation for recurrent vasovagal syncope: Important questions need to be answered. Heart Rhythm. 2021 [Epub ahead of print], doi: 10.1016/j.hrthm.2021.08.032, indexed in Pubmed: 34481983.

93. O'Brien E, Murphy J, Tyndall A, et al. Twenty-four-hour ambulatory blood pressure in men and women aged 17 to 80 years: the Allied Irish Bank Study. J Hypertens. 1991; 9(4): 355-360, doi: 10.1097/00004872199104000-00007, indexed in Pubmed: 1646262.

94. Ejaz AA, Sekhon IS, Munjal S. Characteristic findings on 24-h ambulatory blood pressure monitoring in a series of patients with Parkinson's disease. Eur J Intern Med. 2006; 17(6): 417-420, doi: 10.1016/j.ejim.2006.02.020, indexed in Pubmed: 16962949. 